$\gg$ epad

Vol. 2, N. 1, Abril/2018 


\title{
FATORES QUE INFLUENCIAM A ESCOLHA DE MARCAS E O COMPORTAMENTO DE COMPRA DE CONSUMIDORES DO SEGMENTO DE MODA EM CUIABÁ - MT: Similaridades e Diferenças entre Gêneros
}

\section{FACTORS THAT INFLUENCE THE CHOICE OF BRANDS AND THE BUYING BEHAVIOR FROM CONSUMERS IN THE FASHION SEGMENT IN CUIABÁ - MT: Similarities and Differences between Genres}

\author{
Gabriela Marques Poio \\ Universidade Federal de Mato Grosso \\ https://orcid.org/0000-0001-8554-5605 \\ Francisco Mirialdo Chaves Trigueiro \\ Universidade Federal de Mato Grosso \\ https://orcid.org/0000-0002-4704-2764 \\ Diogo Barbosa Leite \\ Instituto Federal de Mato Grosso \\ https://orcid.org0000-0002-8490-0502
}

\section{RESUMO}

Atualmente, os consumidores são expostos a inúmeras formas de propaganda e ações de marketing das mais variadas marcas, principalmente do segmento de moda. Essa reação observada pelos varejistas da moda pode ser explicada pela crescente diminuição da força das marcas no país, bem como, pela tendência de não fidelidade às marcas por parte dos consumidores. Diante desse contexto, o presente estudo objetivou compreender os diferentes fatores que influenciam na escolha de marcas e no comportamento de compra de homens e mulheres no segmento de moda, buscando analisar similaridades e diferenças entre os gêneros. Para isso, realizou-se um levantamento não probabilístico com consumidores de moda do gênero masculino e feminino. Os principais resultados obtidos apontam diferenças significativas entre os gêneros, como a frequência de compra, fonte de busca por informações, elementos avaliados no pós-compra e estratégias de marketing apontadas pelos consumidores. Entre as semelhanças mais significativas, o estudo encontrou as necessidades como fator associado ao ato de comprar, baixa fidelidade a qualquer marca e fatores considerados no momento da compra, como preço e design / estilo dos produtos de moda.

Palavras-chave: Marketing de varejo. Comportamento do consumidor. Moda. Gênero.

\begin{abstract}
Consumers are exposed to numerous forms of advertising and marketing activities of various brands, especially in the fashion segment. This reaction observed by fashion retailers can be explained by the increasing decline in the strength of brands in the country, as well as the consumers' tendency to not be brand loyal. In this context, the present study aimed to understand the various factors that influence the choice of brands and buying behavior of men and women in the fashion segment, seeking to analyze similarities and differences between
\end{abstract}


genders. For this, a non-probabilistic survey with male and female fashion consumers was conducted. The main results obtained showed significant differences between genres, such as frequency of purchase, information research source, elements assessed in the post-purchase phase and marketing strategies pointed out by consumers. Among the most significant similarities, the study found the necessities as a factor associated with the act of buying, low fidelity to any brand and the factors taken into consideration at the time of purchase, such as price and design/style of fashion products.

Keywords: Retail Marketing. Consumer behavior. Fashion. Gender.

\section{INTRODUÇÃO}

A história mostra que a partir da segunda metade do século XX, mudanças sociais, políticas, econômicas e, principalmente tecnológicas passaram a ocorrer em grande velocidade transformando a sociedade ocidental cada vez mais orientada para o consumo (ARAÚJO JR, 2013). Nesse sentido, surge um cenário altamente competitivo, no qual empresas buscam consolidar suas marcas na mente dos consumidores como meio de promoção. Para tanto, compreender o comportamento do consumidor passou a ser uma necessidade vital para as empresas que desejam se firmar no mercado e conquistar sucesso em sua atuação. O ponto de partida para conhecer e satisfazer as necessidades dos clientes-alvo é tentar compreender o comportamento do consumidor (KOTLER, 2000). Deve-se estudar como pessoas, grupos e organizações selecionam, compram, usam e descartam artigos, serviços, ideias ou experiências para satisfazer suas necessidades.

O segmento da moda insere-se nesse contexto de volatilidade, observado a partir da segunda metade do século XX. Para desenvolver o marketing de moda deve-se ter percepção para entender o mercado e seus consumidores, descobrindo tendências e desenvolvendo produtos que encantem seus clientes. Vivemos em uma sociedade em que a moda, assim como o culto a aparência, já não se limita ao consumo feminino. A partir da década de 1990, ambos os gêneros têm apostado no "culto" a aparência, sendo considerados consumidores assíduos de moda (SILVA, 2008).

Diversas empresas vêm desenvolvendo produtos específicos para homens, principalmente, no setor de moda e de cosméticos. Em contrapartida, se comparado há décadas passadas, nas quais empresas somavam esforços quase que em sua totalidade para atender aos desejos femininos. De toda forma, pode haver semelhanças e diferenças no comportamento entre homens e mulheres no que diz respeito à moda.

Segundo Grohmann et al. (2012), estudos já comprovaram que homens e mulheres podem agir de formas distintas em diversos aspectos, como por exemplo no envolvimento com o produto (KINLEY; CONRAD; BROWN, 1999), intenção de compra (DARLEY; LUETHGE; THATTE, 2008), escolha de mídia (OKAZAKI; HIROSE, 2009) e assimilação de propagandas (TAN; LING; THENG, 2002).

Isso se confirma também em pesquisas, ao se afirmar que "a força do branding no Brasil chegou ao topo de sua evolução em 2011, quando atingiu US\$ 76,9 bilhões. No ano seguinte, sofreu queda para US\$ 59 bilhões e, neste ano, chega agora a US\$ 53,4 bilhões" (IBOPE, 2013). Ao analisar esses indicadores, constata-se um declínio do desempenho das marcas, tanto em termos de valor, quanto em promoção frente aos seus consumidores.

Diante do exposto, chega-se ao objetivo principal desta investigação, que visa destacar os diferentes fatores que influenciam na escolha de marcas e no comportamento de compra de 
homens e mulheres no segmento de moda. Da mesma maneira, elencam-se como objetivos específicos necessários para realização do objetivo geral: Descrever os fatores que influenciam nas escolhas de marcas e comportamento de compra do consumidor; Pesquisar a influência que as marcas exercem sobre os entrevistados e apontar quais são os principais aspectos levados em consideração no momento da compra, considerando as similaridades e diferenças entre homens e mulheres e; Comparar a percepção dos consumidores em relação às estratégias das marcas.

Por fim, a problemática norteadora para o presente artigo baseia-se no seguinte questionamento: na decisão de compra, as marcas podem influenciar homens e mulheres de maneira diferente no comportamento de compra e consumo no segmento da moda? Diante desses cenários de incerteza e diminuição da força das marcas no país, mostra- se de extrema relevância o presente estudo, no sentido de conhecer o consumidor e suas necessidades, apontar o que ele deseja e, não somente, suprir suas necessidades, mas oferecer produtos/serviços que superem seus anseios e desejos.

\section{VAREJO E COMPORTAMENTO DO CONSUMIDOR}

"O marketing está em toda parte. Formal ou informalmente, pessoas e organizações envolvem-se em um grande número de atividades que poderiam ser chamadas de marketing" (KOTLER, KELLER, 2006, p. 2). Tal marketing tem se tornado um ingrediente indispensável para o sucesso nos negócios, pois não é suficiente apenas uma organização possuir setores como finanças, operações e contabilidade bem estruturados e funcionando; é necessário que exista demanda para os produtos produzidos. Para tanto, atribui-se grande relevância a área de marketing, que não se limita em ser apenas um setor fechado, mas sim, uma área do conhecimento a ser estudada e explorada com o intuito de maximizar os resultados pretendidos pelas empresas, procurando identificar, conhecer, atrair e manter os clientes na organização (KOTLER, KELLER, 2006).

Segundo Vieira (2004), o marketing não é mais o mesmo. Aliás, ano após ano, o vem sofrendo transformações e ganhando cada vez mais facções: marketing de acesso, marketing de permissão, gonzo marketing, marketing radical, marketing titânico, marketing hipnótico, marketing de guerrilha, marketing pessoal, marketing político. Diante dessas constantes mudanças que vem ocorrendo, não só o marketing, mas todo o ambiente de negócios, tornandoo cada vez mais dinâmico e competitivo. Há necessidade de entender o marketing em seu sentido mais intrínseco e as práticas a ele atreladas, em atender as demandas do mercado consumidor com eficiência, eficácia e efetividade.

Diante dos conceitos expostos acima, constata-se suma importância que os profissionais da área se atentem para quais são as reais necessidades dos consumidores e, a partir disso, o que pode ser desenvolvido por eles para que essas necessidades sejam traduzidas em desejos por determinado produto/serviço. À medida que o homem vai sendo exposto a objetos que despertam seu interesse e desejo, as empresas tentam fornecer produtos e serviços que satisfaçam esses desejos (KOTLER; ARMSTRONG, 1995).

Cabe aos estrategistas de marketing desenvolver ações que excedam ao máximo as expectativas dos clientes, dando muito mais do que o esperado através da criação de valor acima da média, com o intuito de alcançar um estágio de fascinação para com o produto/serviço e, consequentemente, com a empresa e sua marca. A Análise ambiental, Comportamento do consumidor, Pesquisa e Segmentação de mercado e o Composto de marketing são funções que devem ser desenvolvidas com maestria para que os esforços de marketing sejam válidos e, com isso, os objetivos propostos pela organização sejam alcançados. 
Como primeira função tem-se a Análise ambiental, sendo considerada como a prática de rastrear as mudanças externas que podem afetar o mercado, incluindo demanda por bens e serviços (CHURCHILL; PETER, 2000). Estes ambientes são enormemente suscetíveis a mudanças, oferecendo oportunidades e ameaças as organizações. De acordo com Kotler e Armstrong (1995), as empresas bem-sucedidas sabem que são vitais a observação e adaptação constantes às mudanças deste ambiente.

O Comportamento do consumidor apresenta duas funções principais que devem ser conhecidas para o sucesso de qualquer organização. Para Schiffman e Kanuk (2000), são o entendimento do consumo como parte da vida dos indivíduos e a capacitação das empresas para compreender esses indivíduos. Perceber o modo como o consumidor pensa e se porta é fundamental para o grande desempenho de um produto ou serviço no mercado. A "pesquisa de mercado é uma forma sistemática de coleta, registro e análise de dados relativos a problemas ou oportunidades de marketing e pode ser realizada de forma constante ou para resolver um problema específico" (LAS CASAS, 2009, p. 90). É de fundamental relevância para conhecer a fundo seus mercados e desenvolver estratégicas no sentido de atender e superar as necessidades e desejos dos clientes da organização.

Segundo Boone e Kurtz (2009), a divisão do mercado total em grupos menores e relativamente homogêneos é chamada Segmentação de mercado. Essa função deve ser utilizada por profissionais de marketing para determinar qual é o público que a empresa tem maior interesse em atingir com as ações de marketing.

Por fim, tem-se como principal função o Composto de marketing, também conhecido como 4 Ps (produto, preço, praça, promoção). "A Administração deve estudar o mercado (suas tendências), o consumidor (suas preferências), persuadi-los (pela propaganda), promover o produto e organizar sua distribuição" (SANT'ANNA; ROCHA; GARCIA, 2009, p. 17). Esses quatro fatores do mix de marketing são inter-relacionados, ou seja, decisões em uma área afetam todas as outras e "juntos, esses quatro fatores devem satisfazer às necessidades de mercadosalvo e, ao mesmo tempo, atingir os objetivos de marketing da organização" (ETZEL; WALKER; STANTON, 2001, p. 60).

A distribuição de produtos ao consumidor inicia-se com o produtor e termina com o consumidor final. Entre os dois geralmente há pelo menos um intermediário - um varejista (ETZEL; WALKER; STANTON, 2001). Existem atualmente inúmeros varejistas bemsucedidos no ramo da moda, tais como as grandes lojas de departamentos, e para cada um deles, milhares de pequenos varejistas atendendo diversas áreas. Porém, apesar de diferenças entre os grandes e os pequenos varejistas, os mesmos apresentam dois aspectos importantes em comum: "eles formam a ligação entre os produtores e os consumidores finais e desempenham serviços valiosos para ambos" (ETZEL; WALKER; STANTON, 2001, p. 378). Boone e Kurtz (2009) acrescentam que tanto os grandes quanto os pequenos varejistas realizam as principais atividades do canal: criar tempo, local e unidades de título de propriedade.

O varejo inclui todas as atividades relativas à venda de produtos ou serviços diretamente ao consumidor final, para uso pessoal e não comercial. Muitas instituições - fabricantes, atacadistas e varejistas - fazem varejo. Não importa como os produtos ou serviços são vendidos, se pessoalmente, por telefone, pela internet, ou onde eles são vendidos, se em uma loja, na casa do consumidor, na rua (KOTLER, 2006). De modo similar, "é o processo de compra de produtos em quantidade relativamente grande dos produtores atacadistas e outros fornecedores e posterior venda em quantidades menores ao consumidor final" (RICHTER, 1954, p.53). Sendo assim, pode-se concluir que o varejo tem como condição básica de constituição a comercialização de produtos ou serviços a consumidores finais, não importando a natureza da organização que o exerce e tampouco o local em que está sendo praticado. 
Diante da evolução do conceito e história do varejo, pode-se observar que antigamente, os varejistas costumavam reter clientes oferecendo uma localização conveniente, sortimentos especiais ou exclusivos de produtos, serviços mais completos ou melhores que os da concorrência e cartões de crédito próprio. Porém, tudo isso mudou e está mudando. Atualmente, marcas como Calvin Klein, Izod e Levi's são encontradas na maioria das lojas de departamentos, em suas próprias lojas, em lojas de pontas de estoque e em lojas de desconto. Na busca por volume, os fabricantes de grandes marcas colocam seus produtos em todos os lugares e, como resultado, os artigos vendidos nas lojas de varejo estão cada vez mais parecidos (KOTLER; KELLER, 2006).

Por isso, um aspecto relevante que deve ser desenvolvido por gestores de marketing do setor varejista da moda, ações que busquem atrair, manter e fidelizar clientes, os quais demonstram, cada vez mais, serem compradores sagazes e exigentes. Algumas das ações que podem ser adotadas por varejistas da moda são: abertura de filiais em shoppings centers, onde há estacionamento suficiente e as rendas familiares são maiores, em promover liquidações mais frequentes, remodelar suas lojas, lançamento de marcas próprias e experimentar vendas pelo correio e por telemarketing (KOTLER; KELLER, 2006).

Segundo Gouveia et al. (2011), uma das grandes dificuldades do varejo é entender o consumidor. Este a cada momento muda seus hábitos de compra e isso faz com que sejam encontradas novas alternativas para as empresas atrair mais clientes e ganhar competitividade diante de seus concorrentes. Com isso, pode-se concluir que é de fundamental importância que o consumidor seja conhecido e entendido em sua forma mais intrínseca para que os objetivos organizacionais do marketing de varejo sejam atingidos. Para isso, faz-se necessário o estudo do comportamento do consumidor e quais fatores os influenciam na compra de um produto ou não.

"homem se define de imediato como proprietário privado, quer dizer, como possuidor exclusivo que afirma sua personalidade, se distingue do outro e se relaciona com o outro por meio dessa posse exclusiva: a propriedade privada é seu modo de existência pessoal, distintivo e, em consequência, sua vida essencial" (MARX, 1844 apud GIGLIO, 2005, p. 1).

O interesse pelo estudo do consumidor não é novo. Desde que se tem registro, as relações de troca e escambo entre povos vêm tentando ser explicadas com a criação de explicações e hipóteses, as quais tentam definir o comportamento de compra do consumidor e quais fatores o fazem comprar um produto/serviço em detrimento de outro. "Há 160 anos, Marx já teorizava sobre a essência da posse, o que hoje gera estudos sobre a sociedade de consumo" (GIGLIO, 2005, p. 1).

De acordo com Vieira (2002), a necessidade de maior compreensão dos propósitos, objetivos, reações e maneiras de agir do consumidor não é de hoje: há muito tempo atrás, Henry Ford ignorou a necessidade do consumidor e se viu obrigado a fazer modificações drásticas em sua linha de montagem, gerando assim novos produtos para conquistar a satisfação do cliente.

O comportamento do consumidor é o estudo dos processos envolvidos quando indivíduos ou grupos selecionam, compram, usam, dispõem de produtos, serviços, ideias ou expectativas para satisfazer necessidades e desejos. O estudo do tema se mostra de extrema relevância atualmente, pois os profissionais de marketing devem conhecer, estudar e monitorar constantemente os consumidores e seus comportamentos de compra, com o intuito de descobrir oportunidades e ameaças aos seus negócios com a possível insatisfação ou recusa de seus clientes a determinados tipos de produtos (SOLOMON, 2002).

Como conceito central do tema, temos o consumidor, o qual é dotado de motivação para atingir o que deseja e buscar determinadas ambições, é também dotado de personalidade, o que 
faz com que alguns consumidores tenham maior atração por determinado tipo de produto do que outro, de percepção diferenciada da realidade, pois alguns percebem uma propaganda com agrado, enquanto outros as consideram ridículas, e, por fim, o consumidor tem a capacidade de aprender os nomes dos produtos, o nome das lojas e sua localização. Ele aprende também como utilizar determinados produtos, como espelhar-se neles, como precisar deles. Tal como o indivíduo com todas as suas características pessoais, o consumo traz, dentro de si mesmo, elementos que vão interagir com estímulos exteriores (produtos, propagandas, marcas) e que vão fazer com que ele tenha um comportamento até certo ponto previsível ou não (KARSAKLIAN, 2000).

O comportamento de compra é influenciado por diversos fatores pessoais e interpessoais que devem ser analisados para um correto diagnóstico do consumidor e de seu comportamento, dentre eles destacam-se os fatores culturais, sociais, pessoais e psicológicos, os quais serão abordados com base nos principais autores a respeito do tema em questão. (SCHIFFMAN; KANUK, 2005; KOTLER; KELLER, 2006; BOONE; KURTZ 2009).

\section{Marcas e Brand Equity}

O acelerado avanço tecnológico dos processos de desenvolvimento de produtos e, também, de todo o processo industrial, tem permitido que a maioria dos fabricantes ofereçam ao mercado produtos que, além de apresentarem as mesmas especificações técnicas e, por conseguinte, a mesma qualidade, apresentam os mesmos canais de distribuição e meios de comunicação, o que resulta em pressões idênticas de demanda. A combinação de todos esses aspectos leva, inevitavelmente, a uma maior valorização da marca como elemento exclusivo de diferenciação. Diante disso, uma marca passa a significar não somente o produto real, mas incorpora um conjunto de valores e atributos intangíveis que contribuem para diferenciá-la daqueles que lhe são similares (PINHO, 1996).

Rocha e Ponte (2005) afirmam que em uma época em que a homogeneidade tecnológica nivelou muitas empresas, resta aos ativos intangíveis, em particular às marcas, a responsabilidade de tornar as empresas competitivamente diferenciadas. Em outras palavras, pode-se afirmar que a marca adiciona ou subtrai valor de um produto mediante a lealdade que permite estabelecer com o consumidor, a notoriedade que permite a criação de demais linhas de produtos, a qualidade transmitida e as associações realizadas pelo consumidor e que a distinguem das demais.

As marcas assumem destaque nas relações de compra e venda indo além da ideia de meras facilitadoras das transações comerciais para transformar-se em poderosos e complexos signos de posicionamento social e de ser no mundo (PEREZ, 2004).

Diante disso, tem-se o conceito de marca utilizado em marketing desenvolvido pela American Marketing Association (AMA), conforme Perez (2005 apud KOTLER, 1998, p. 393), como sendo "um nome, termo, sinal, símbolo ou combinação dos mesmos, que têm o propósito de identificar bens ou serviços de um vendedor ou grupo de vendedores e de diferenciá-los de concorrentes". Diante de tais conceitos pode-se concluir que a marca passa a significar não somente o produto real, mas incorpora um conjunto de valores que contribuem para diferenciála daquelas que lhe são similares. Cabe aos profissionais de marketing reconhecerem que as marcas têm uma influência poderosa sobre o comportamento do consumidor e, além disso, criar identidades fortes para suas marcas, fazendo com que consumidores sejam atraídos por elas e criem uma relação estreita com as mesmas, tornando-se consumidores fiéis, que além de meros consumidores, tornam-se uma das principais fontes de divulgação da marca. 
Já o termo Brand equity significa o valor da marca, ou seja, um conjunto de passivos e ativos ligados a uma marca, seu nome e seu símbolo, que se somam ou se subtraem do valor proporcionado por um produto ou serviço para a empresa e seus consumidores (AAKER, 1998). Brand equity é o valor agregado atribuído a produtos e serviços. Esse valor pode se refletir no modo como os consumidores pensam, sentem e agem em relação à marca, bem como nos preços, na participação de mercado e na lucratividade que a marca proporciona à empresa, sendo um importante ativo intangível que representa valor psicológico e financeiro para a empresa (KOTLER; KELLER, 2006).

Algumas marcas valem mais do que uma empresa e suas instalações, por mais grandiosas que sejam. A influência da marca para o sucesso da empresa torna-se cada vez mais incontestável diante do seu poder demonstrado em criar associações positivas que possam garantir ao produto/serviço firmes posições no mercado e na mente dos consumidores, persistindo durante um longo período e ainda sendo capazes de resistir a grande concorrência existente no mercado global. Segundo Hiller (2012), podemos dizer que a Diesel, por exemplo, tem um brand equity fantástico, pois quando alguém paga cerca de $\mathrm{R} \$ 2$ mil para ter uma calça jeans, a pessoa poderia comprar outra, fisicamente parecida, por módicos $\mathrm{R} \$ 49,90$. Dessa forma, todo esforço de branding que a empresa imprime na sua marca deve visar ao aumento do brand equity do produto.

Ao integrar os conceitos de marcas e brand equity pode-se concluir que o branding é um método de gestão das relações entre marca e o mercado, que objetiva criar um vínculo entre as organizações e o seu público através do diferencial proporcionado pelo patrimônio da marca (brand equity). Embora este fenômeno tenha sido intensificado com a Revolução Industrial, até o início do século XX, as empresas parecem não ter descoberto todas as potencialidades que as marcas podem apresentar. Os europeus quando se instalaram na América do Norte, trouxeram a prática de utilizar marcas. Os primeiros a se utilizarem de marcas com patentes registradas nos Estados Unidos foram os fabricantes de remédios e indústrias tabagistas.

No século XIX, a preocupação em relação às garantias e registros das marcas ocasionou a Lei de Marcas de Mercadoria na Inglaterra (1862), a Lei Federal da Marca de Comércio nos EUA (1870) e a Lei para a Proteção de Marcas na Alemanha. Algumas marcas criadas em 1860 e 1870 existem até os dias de hoje e mostram-se firmes no mercado, como, por exemplo, Quaker Oats, Ivory Soap e Borden Condensed Milk.

Por volta de 1930, ganhou novas funções e foi a General Motors quem primeiro elaborou uma estratégia de marcas, criando um leque, não apenas de produtos, mas também de marcas inspiradas em diversos conceitos. Desde então, as marcas tornaram-se objetos de estratégias específicas dentro de uma organização, as quais devem ser desenvolvidas com maestria por profissionais de marketing, fazendo com que produtos sejam concebidos e fabricados a partir de conceitos articulados e definidos como o território da marca (PEREZ, 2004; KELLER; MACHADO, 2006; OLIVEIRA; LUCE, 2011).

Cabe destacar alguns dos elementos que compõem uma marca, como o nome, logotipo e logomarca, forma e design e a embalagem. (PEREZ, 2004; BOONE; KURTZ 2009; HILLER 2012). A American Marketing Association define nome da marca como a parte da marca composta de palavras ou letras que formam o nome que identifica e diferencia as ofertas da empresa e as dos concorrentes. Imaginariamente, a marca desempenha o papel de criador do produto, sendo integralmente responsável por ele; o logotipo é a imagem ou figura que representa sua marca, sendo a parte que pode ser identificada, mas não falada pelo consumidor. Como exemplo, temos a maçã da Apple ou o jacaré como símbolo da Lacoste; a forma e o design são questões fundamentais que permeiam as decisões quanto à estética, à funcionalidade e à percepção que se deseja para um produto; por fim, a embalagem, a qual pode representar 
uma grande influência nas decisões de compra dos consumidores. Cada vez mais, os profissionais de marketing têm adotado métodos sofisticados ao tomarem decisões sobre embalagens, com o intuito de atrair mais clientes.

Portanto, as marcas e o brand equity tratam de práticas de gestão que objetivam aumentar a participação de mercado das organizações, elevando suas marcas a categorias de ativos estratégicos, disseminando assim a cultura da marca e proporcionando valor para todos aqueles que são relevantes para manter a competitividade do negócio: investidores, funcionários, consumidores, parceiros, contribuindo assim para a sustentabilidade e longevidade das organizações. Tais conceitos demonstram-se de extrema relevância, principalmente, no ramo da moda, por constituírem-se de fortes fatores que contribuem para a diferenciação e perenidade dos negócios, por se tratar de um setor altamente disputado e competitivo.

\section{PROCEDIMENTOS METODOLÓGICOS}

Esta seção descreve quais metodologias e instrumentos que foram empregados no desenvolvimento do estudo. Diante disso, o tipo de pesquisa utilizada para o estudo foi a exploratória, com o intuito de adquirir conhecimento de fontes publicadas, seja de autores renomados ou de periódicos publicados a respeito do tema, no sentido de obter embasamento teórico para a construção da pesquisa e, por conseguinte, do trabalho como um todo. "As pesquisas exploratórias têm como propósito proporcionar maior familiaridade com o problema, com vista a torná-lo mais explícito ou a construir hipóteses" (GIL, 2010, p. 27). Assim, o principal objetivo de se fazer a pesquisa exploratória é o de adquirir conhecimento e aprimorálo para uma melhor construção de ideias e posicionamentos a respeito do tema.

A pesquisa exploratória, consequentemente, seguida de uma pesquisa bibliográfica, a qual fornece material teórico, como livros, revistas, jornais, teses, dissertações e periódicos ligados ao assunto para embasar o estudo. Segundo Vergara (2009, p. 43), "a pesquisa bibliográfica é o estudo sistematizado desenvolvido com base em material publicado em livros, revistas, jornais, redes eletrônicas, isto é material acessível ao público em geral". As principais fontes utilizadas no presente estudos foram livros, revistas, artigos e teses, periódicos e o meio eletrônico.

Após o estudo sistemático da bibliografia existente acerca do tema em questão, realizouse a pesquisa de levantamento, objetivando entender o comportamento do consumidor, já que de acordo com Gil (2010, p. 37), os levantamentos são "muito eficazes para problemas menos delicados, como preferência eleitoral e comportamento do consumidor". O levantamento fora realizado na cidade de Cuiabá, Mato Grosso, durante o mês de dezembro de 2013. Como suporte a esta técnica, utilizou-se como instrumento de coleta de dados um questionário estruturado. Anterior à aplicação dos questionários, foi realizada pré-teste entre os no mês novembro do mesmo ano, com alunos no oitavo semestre do curso de Administração da Universidade Federal de Mato Grosso.

O universo da pesquisa constitui-se em consumidores de roupas, não sendo considerada segmentação por idade, apenas por gênero. De um modo geral, os levantamentos abrangem um universo de elementos tão grande que se torna impossível considerá-los em sua totalidade. Por essa razão, o mais frequente é trabalhar com uma amostra, ou seja, com uma pequena parte dos elementos que compõe o universo (GIL, 2010, p. 109). Diante disso, utilizou-se uma amostra de duzentas e dezessete pessoas por conveniência, não aleatória ou não probabilística, "sendo considerada aquela em que a seleção dos elementos da população para compor a amostra 
depende ao menos em parte do julgamento do pesquisador ou do entrevistador no campo" (MATTAR, 2001, p. 132).

\section{APRESENTAÇÃO E DISCUSSÃO DOS RESULTADOS}

Durante a investigação, foram entrevistadas duzentas e dezessete pessoas, das quais cento e vinte e cinco são mulheres, correspondendo a $58 \%$ do total, e noventa e dois homens, equivalendo-se a $42 \%$ da população de entrevistados.

Com relação à influência das marcas sobre os consumidores, tem-se que de cento e vinte e cinco mulheres que participaram da pesquisa, $33 \%$ declararam levar em consideração a marca das roupas ao comprá-las, em oposição aos $67 \%$, as quais declararam não ser influenciadas por marcas. Já do gênero masculino, de noventa e dois participantes, 53\% declararam ser influenciados por marcas contra $47 \%$ que declararam não ser.

Frente a tantas opções e ao alto sortimento de produtos e serviços, os consumidores deixaram de ser fiéis às marcas há algum tempo. Isso porque atualmente, em praticamente todos os segmentos de mercado, os consumidores podem optar pelas mais diferentes marcas, nacionais ou estrangeiras, considerando-se que a abertura dos mercados proporcionou um acesso a produtos e serviços até então inimagináveis (PEREIRA, 2009). Diante disso, os resultados mostram uma tendência de que, cada vez mais, os clientes têm se tornado menos fiéis às marcas.

Segundo dados do Target Group Index do IBOPE Media (2012), 83\% da população procura por ofertas e descontos no momento de consumir, este percentual é o mesmo, independente da classe econômica analisada, sendo considerado um dos fatores que explicam a afirmação inicial, no qual consumidores substituem a preferência por marcas favoritas à preferência por um preço mais baixo e justo, optando por comprar produtos em promoções com preços mais acessíveis.

Em se tratando do gênero masculino, segundo Underhill (1999), pesquisas cronometradas revelaram que os homens gastam menos tempo olhando as vitrines, pois apenas olham o que tem intenção de comprar. Fator que caracteriza um comportamento mais estável de compra, no qual preferem continuar comprando da mesma marca por tornar a compra mais acertada, e por olharem apenas os produtos que tem a intenção de comprar. Os homens evitam perder tempo pesquisando outras marcas, preços e produtos, optando por compras mais acertadas e de marcas já conhecidas. Também, os homens estão mais envolvidos com a compra de suas roupas (UNDERHILL,1999), o que já fora um papel quase exclusivo das mulheres, representando assertividade dos dados da investigação.

A fim de estratificar os dados levantados, apresentam-se no Quadro 1 os itens de comportamento de compra por gênero e influência por marca. Diante desses dados, podem-se analisar as diferenças entre mulheres e homens, as quais são apresentadas no sentido de que as mulheres preferem comprar roupas com mais frequência e em menores quantidades, gostam de olhar as vitrines e, até mesmo, comprar por oportunidade, aproveitando as promoções. Outro fator que pode ser relevante, para as mulheres comprar com mais frequência que os homens, e por algumas comprarem não só para si mesmas, mas também, para seus filhos e maridos. Já os homens compram com menor frequência e em maiores quantidades. Como afirma Andreasi (2011), os homens andam mais rápido que as mulheres, gastam menos tempo olhando o produto e não gostam de perguntar onde as coisas estão. 
Quadro 1: Descrição de itens de comportamento de compra por Gênero e Influência por marca.

\begin{tabular}{|c|c|c|c|c|}
\hline \multirow{2}{*}{$\begin{array}{c}\text { Variável } \\
\text { Gênero }\end{array}$} & \multicolumn{2}{|c|}{$\begin{array}{c}\text { Declarou sofrer } \\
\text { influência pela marca }\end{array}$} & \multicolumn{2}{|c|}{$\begin{array}{c}\text { Declarou não sofrer } \\
\text { influência pela marca }\end{array}$} \\
\hline & Masculino & Feminino & Masculino & Feminino \\
\hline \multicolumn{5}{|c|}{ Frequência de compra } \\
\hline Anual & $4,88 \%$ & $10,20 \%$ & $20,93 \%$ & $9,52 \%$ \\
\hline Semestral & $12,19 \%$ & $20,40 \%$ & $20,93 \%$ & $17,86 \%$ \\
\hline Trimestral & $21,95 \%$ & $26,53 \%$ & $23,26 \%$ & $20,24 \%$ \\
\hline Bimestral & $31,71 \%$ & $18,37 \%$ & $20,93 \%$ & $21,43 \%$ \\
\hline Mensal & $26,83 \%$ & $24,49 \%$ & $13,95 \%$ & $30,95 \%$ \\
\hline Semanal & $2,44 \%$ & $0 \%$ & $0 \%$ & $0 \%$ \\
\hline \multicolumn{5}{|c|}{ Fator associado ao ato de compra } \\
\hline Ato compulsivo & $0 \%$ & $0 \%$ & $0 \%$ & $0 \%$ \\
\hline Um desconforto & $0 \%$ & $0 \%$ & $1,19 \%$ & $0 \%$ \\
\hline Ato impulsivo & $2,04 \%$ & $0 \%$ & $3,57 \%$ & $0 \%$ \\
\hline Lazer & $2,04 \%$ & $0 \%$ & $3,57 \%$ & $2,33 \%$ \\
\hline Seguir a moda & $2,04 \%$ & $4,88 \%$ & $4,76 \%$ & $2,33 \%$ \\
\hline Desejo & $8,16 \%$ & $9,76 \%$ & $10,72 \%$ & $6,97 \%$ \\
\hline Aproveitar promoções & $10,20 \%$ & $36,58 \%$ & $21,43 \%$ & $11,63 \%$ \\
\hline Necessidade básica & $75,52 \%$ & $48,78 \%$ & $54,76 \%$ & $76,74 \%$ \\
\hline \multicolumn{5}{|c|}{ Desencadeamento da necessidade de compra } \\
\hline Para acompanhar amigos & $6,85 \%$ & $1,56 \%$ & $0 \%$ & $0,76 \%$ \\
\hline Atualizar-se a moda & $6,85 \%$ & $9,38 \%$ & $1,52 \%$ & $3,79 \%$ \\
\hline Percebe alterações do manequim & $15,07 \%$ & $7,81 \%$ & $10,60 \%$ & $10,61 \%$ \\
\hline Renovação do vestuário & $47,94 \%$ & $41,19 \%$ & $28,79 \%$ & $39,39 \%$ \\
\hline Participar de eventos/ocasiões & $20,55 \%$ & $39,06 \%$ & $56,06 \%$ & $41,66 \%$ \\
\hline Outros & $2,76 \%$ & $0 \%$ & $3,03 \%$ & $3,76 \%$ \\
\hline \multicolumn{5}{|c|}{ Forma de decisão de compra } \\
\hline Bem planejada & $38,77 \%$ & $21,95 \%$ & $37,21 \%$ & $22,62 \%$ \\
\hline Mais ou menos planejada & $46,95 \%$ & $73,17 \%$ & $44,19 \%$ & $54,76 \%$ \\
\hline Sem planejar & $8,16 \%$ & $2,44 \%$ & $18,60 \%$ & $16,67 \%$ \\
\hline Impulsiva & $6,12 \%$ & $2,44 \%$ & $0 \%$ & $5,95 \%$ \\
\hline \multicolumn{5}{|c|}{ Fatores de influência na compra } \\
\hline Amigos & $3,42 \%$ & $0,87 \%$ & $0 \%$ & $0 \%$ \\
\hline Família & $1,71 \%$ & $3,47 \%$ & $1,65 \%$ & $0,44 \%$ \\
\hline Variedade e diversidade de produtos & $5,98 \%$ & $6,96 \%$ & $4,13 \%$ & $4,89 \%$ \\
\hline Localização da loja & $5,98 \%$ & $6,96 \%$ & $10,74 \%$ & $7,56 \%$ \\
\hline Comodidade para a compra & $12,82 \%$ & $11,30 \%$ & $13,22 \%$ & $12,89 \%$ \\
\hline Promoções e liquidações constantes & $17,09 \%$ & $20,87 \%$ & $14,88 \%$ & $17,78 \%$ \\
\hline Design/estilo dos produtos & $24,79 \%$ & $24,35 \%$ & $22,31 \%$ & $24,89 \%$ \\
\hline Preço & $28,21 \%$ & $25,22 \%$ & $26,46 \%$ & $28,89 \%$ \\
\hline Outros & $0 \%$ & $0 \%$ & $6,61 \%$ & $2,66 \%$ \\
\hline \multicolumn{5}{|c|}{ Elementos avaliados no pós-compra } \\
\hline Adequou-se a moda & $2,33 \%$ & $4,23 \%$ & $0 \%$ & $1,78 \%$ \\
\hline Atendimento pós-compra & $0 \%$ & $2,82 \%$ & $0 \%$ & $2,38 \%$ \\
\hline Praticidade no manuseio & $3,49 \%$ & $0 \%$ & $9,30 \%$ & $8,33 \%$ \\
\hline Elogios recebidos & $12,19 \%$ & $8,45 \%$ & $2,33 \%$ & $8,33 \%$ \\
\hline Design/estilo & $22,09 \%$ & $26,76 \%$ & $17,44 \%$ & $19,64 \%$ \\
\hline Durabilidade & $32,56 \%$ & $36,61 \%$ & $36,05 \%$ & $27,98 \%$ \\
\hline Conforto & $26,74 \%$ & $21,13 \%$ & $34,88 \%$ & $30,96 \%$ \\
\hline
\end{tabular}


Em comparação com os entrevistados não influenciados por marcas, pode-se perceber que a frequência de compra de roupas aumenta consideravelmente entre os gêneros, principalmente, entre as mulheres. Os homens aumentam a frequência de compra mensal e isso demonstra que quando a marca influencia, o tempo de compra é mais bem definido, já que depende da oferta de novas peças da marca no mercado, em contraste para os não influenciados por marcas, que ficam mais livres para comprar de acordo com outras influências como as necessidades de urgência, preço ou promoções.

A necessidade, com $54,8 \%$ entre mulheres e $76,7 \%$ entre homens é apontada como principal fator associado ao ato de comprar roupas para aqueles que não são influenciados por marcas, ou seja, mesmo em quantidades diferentes, pode-se encontrar uma similaridade entre os gêneros na questão necessidade. De acordo com Las Casas (2006), a Teoria das Necessidades de Maslow sugere que as necessidades são dispostas em ordem hierárquica em que os indivíduos procuram satisfazer a uma das necessidades antes de subir para a seguinte. Com isso, a necessidade de vestir-se, sendo considerada uma necessidade básica humana, foi apontada pela maioria dos entrevistados, tanto homens quanto mulheres.

Todo processo de compra, principalmente em relação ao vestuário envolve fatores, como a necessidade de se vestir, o desejo de compra, o bem-estar e a satisfação, entre outros (UNDERHILL, 1999). Todavia é evidente, ao se analisar os dados obtidos observando similaridades e diferenças entre os gêneros, que as porcentagens das opções aproveitar as promoções/liquidações, desejo, tendência em seguir a moda, lazer e ato impulsivo, são maiores para o sexo feminino, pois as mulheres têm mais afinidade com o que se imagina "fazer compras" dada aptidão a experimentação (UNDERHILL, 2009).

Para os que são influenciados por marcas, a necessidade novamente aparece como principal fator associado ao ato de comprar roupas com 48,8\% das mulheres e $75,5 \%$ dos homens. Entretanto, se compararmos com as mulheres que não são influenciadas por marcas, pode-se observar que a porcentagem de mulheres que aponta a necessidade como quesito cai e o fator desejo aumenta consideravelmente para o sexo feminino. De mesmo modo que ocorre aumento mais discreto para o sexo masculino nesse mesmo quesito. Diante disso, pode-se afirmar que os respondentes influenciados por marcas apresentam maior desejo de obter um produto da moda, se comparado com aqueles que não são influenciados, esse fator pode ser explicado pelas ações que são desenvolvidas pelo marketing das marcas da moda, os quais cada vez mais induzem e seduzem os consumidores para que desejem ter seus produtos.

As principais ações de marketing para atrair seus consumidores são as propagandas veiculadas em TVs e revistas e de acordo com dados de uma pesquisa encomendada pela Associação Brasileira da Indústria Têxtil e de Confecção (ABIT) e o Ministério do Desenvolvimento, Indústria e Comércio Exterior (MDIC) para tentar definir os hábitos e costumes do consumidor brasileiro em relação ao vestuário, a televisão é apontada como principal fonte de informação sobre moda, com participação de 72\% e 47,5\% dos entrevistados já compraram produtos de moda por causa de propagandas. Este índice é maior entre as mulheres, com 52,7\% (ABIT; MDIC, 2011).

Em se tratando dos atos de compra impulsivo e compulsivo, respectivamente, citados por 3,6\% das mulheres não influenciadas por marcas e 2,0\% dos homens influenciados por marcas, cabe a sua distinção, a qual de acordo com Almeida (1992), no ato impulsivo, o comprador é visto como um desequilibrado, em que um desejo repentino e espontâneo de compra surge provando um estado de desequilíbrio psicológico entre o prazer de comprar e a realidade de não comprar.

Já, no ato compulsivo, o comprador é visto como dependente da compra, redutora de tensão psicológica e de ansiedade causada pelo prazer de comprar. O comprador nem sempre 
procura a posse de um bem, mas, sobretudo, a redução do estado de tensão, sendo caracterizado como um comportamento anormal ou doentio. A compra por impulso não se confunde com o consumo compulsivo. Enquanto o impulso para comprar um item específico é temporário e se concentra em determinado produto num certo momento, o comprar compulsivo é um comportamento repetitivo, muitas vezes excessivo, como um antídoto para a tensão, ansiedade, depressão ou tédio, que é centrado no processo de comprar, e não nas compras em si (SOLOMON, 2002). Conforme Underhill (2003), 70\% das compras são feitas por impulso. Acompanhada de uma amiga, a mulher fica o dobro de tempo numa loja (UNDERHILL, 2003).

Outro resultado, tanto para os homens não influenciados por marcas, quanto para os influenciados, é que o principal motivo apresentado foi a compra de roupas pela necessidade de renovar o guarda-roupa em função do desgaste. Com isso, é possível afirmar que os homens apresentam um comportamento de compra mais racional se comparado com o das mulheres. Mesmo que as mulheres pesquisem e se informem mais sobre os produtos da moda antes da compra, o comportamento das mesmas é levado mais pela emoção do que pela razão. Na análise de Underhill (1999), as mulheres durante as compras são envolvidas por sentimentos de prazer e satisfação, ao passo que os homens são envolvidos pelo desafio de serem convencidos a compram.

As mulheres querem que uma marca se estenda e penetre em suas vidas tanto quanto for possível. Querem uma marca que fale às suas cabeças e aos seus corações. Que reconheça suas necessidades, valores, padrões e sonhos (POPCORN; MARIGOLD, 2000, p. 30). Com isso, as mulheres tornam-se mais adeptas as marcas da moda que se identificam e acabam optando por seguir as coleções e tendências dessas marcas. Já para os homens, de acordo com Las Casas (2006), um fator que influencia os consumidores é o fato de eles pertencerem a vários grupos ao mesmo tempo. As pessoas têm a tendência de comprar os produtos semelhantes aos outros grupos, sendo consideradas influências primária e altamente influentes.

Infere-se similaridade entre homens e mulheres no que diz respeito à falta de planejamento para a maioria dos entrevistados. No entanto, os resultados mostram mais uma vez o comportamento mais racional da maioria dos homens, que planeja compras, $37,2 \%$ dos homens versus 22,6\% das mulheres. De acordo com Underhill (1999), a compra média dos homens tem um valor mais elevado que a das mulheres. "Eles também são muito mais sugestionáveis do que as mulheres - os homens parecem tão ansiosos por sair da loja que dizem sim para quase tudo", aponta Underhill (1999, p. 91).

Para as mulheres que são influenciadas por marcas, apresentam menor índice de compra por impulso se comparado as que não são influenciadas, com um percentual de $2,4 \%$. Em se tratando de compras mais ou menos planejadas pelas mulheres, este índice saltou de 54,8\% para $73,2 \%$. Porém, é possível observar que os índices de compras sem nenhum planejamento diminuíram se comparado aos entrevistados que não são influenciados por marcas. Tal fato pode ser comprovado, pois os que são influenciados por marcas tem a opção de tornarem suas compras mais planejadas ao visualizar ou vislumbrar as coleções que estão por vir de suas marcas favoritas e esperar tal lançamento, adquirindo os produtos desejo da nova coleção, tornando a compra mais assertiva e planejada. Já para os homens, o aumento mais significativo foi com relação a alternativa impulsiva.

As mulheres procuram, comparam, imaginam o produto em uso e verificam os prós e os contras de um produto em relação a outro, orgulhando-se de sua "capacidade de selecionar a coisa perfeita" (UNDERHILL, 1999). Diante disso, o quesito design/estilo está entre esse "ritual" feminino de analisar os prós e os contras de um produto em relação a outro antes de comprar. Novamente, de acordo com o autor, $60 \%$ dos homens que experimentam uma calça 
jeans compram o produto. Todavia, no caso das mulheres, essa porcentagem é de apenas $25 \%$, confirmando o que foi dito acima.

O preço aparece como o principal fator que influenciam os consumidores no momento da compra de itens da moda, com 28,9\% das mulheres não influenciadas por marcas e 26,5\% dos homens também não influenciados. Para aqueles que declararam sofre influência os dados são $25,2 \%$ das mulheres e 28,2\% dos homens respectivamente. Segundo Underhill (2009, p. 111), $86 \%$ das mulheres consultam as etiquetas de preços ao fazer compras. Somente $72 \%$ dos homens fazem o mesmo. Para um homem, ignorar etiqueta de preço é quase uma medida de sua virilidade. Em consequência, os homens são muito mais facilmente induzidos a gastar em média bem mais que as mulheres, já as mulheres buscam o melhor preço (UNDERHILL, 2009). Porém, tal fato não torna o quesito preço como sendo um grande diferencial entre os gêneros, mas sim, uma similaridade, no sentido de que a grande maioria dos respondentes assume que o fator preço é determinante no momento da compra. Segundo dados da Fecomércio-RJ (2014), revelou que, sem levar com consideração os gêneros, os principais fatores que influenciam a compra de um produto são preço (93\%), conforto (80\%) e beleza (74\%).

Assim, a marca sozinha, mesmo influenciando, não é fator determinante, corroborando com a teoria de Underhill (2009), sobre o declínio da influência das marcas nos dias de hoje, e os resultados dessa pesquisa e de outras fontes, no qual há a tendência de não ser leal a uma ou poucas marcas. Após analisar os dados obtidos pela pesquisa de levantamento, pode-se concluir que, em se tratando das estratégias de marketing que devem ser desenvolvidas pelos varejistas, principalmente do segmento de moda, para atrair cada vez mais clientes comprando seus produtos, estão: uma propaganda bem feita pode mudar a preferência de alguns clientes, a variável preço pode ser usada com frequência para estimular a compra, principalmente no setor da moda, o qual apresenta produtos muito homogêneos, diferindo apenas em poucos quesitos, e, por fim, enfatizar os produtos com características diferenciadas, de maior valor agregado (LAS CASAS, 2006).

Os entrevistados foram questionados quanto ao grau de importância atribuído às estratégias de marketing que devem ser desenvolvidas pelos varejistas da moda em geral. Nesse caso, utilizou-se Escala Likert de cinco pontos, desde a total discordância até total concordância. A média e o desvio-padrão das notas obtidas, para os que se declararam não ser influenciados por marcas e para aqueles que declaram ser, são demonstradas no Quadro 2.

Quadro 2 - Percepção da importância de estratégias por Gênero e Influência de compra.

\begin{tabular}{|c|c|c|c|c|c|c|c|c|}
\hline Variável & \multicolumn{4}{|c|}{$\begin{array}{c}\text { Declarou sofrer } \\
\text { influência pela marca }\end{array}$} & \multicolumn{4}{|c|}{$\begin{array}{l}\text { Declarou não sofrer } \\
\text { influência pela marca }\end{array}$} \\
\hline Gênero & \multicolumn{2}{|c|}{ Feminino } & \multicolumn{2}{|c|}{ Masculino } & \multicolumn{2}{|c|}{ Feminino } & \multicolumn{2}{|c|}{ Masculino } \\
\hline Indicador & Média & DP & Média & DP & Média & $\mathrm{DP}$ & Média & DP \\
\hline Preço e liquidações & 4,15 & 1,2 & 4,16 & 1 & 4,22 & 1,1 & 4,14 & 0,9 \\
\hline Formas e Condições & 3,89 & 1,3 & 3,77 & 1,3 & 4,1 & 1,2 & 3,69 & 1,1 \\
\hline Atendimento na loja & 4,15 & 1,2 & 4,53 & 0,9 & 4,59 & 0,8 & 4,37 & 1,1 \\
\hline Ambi & 3,79 & 1,2 & & 0,8 & 4,05 & 1 & & 1 \\
\hline Pós-venda & 3,2 & 1,3 & 3,33 & 1,3 & 3,63 & 1,1 & 3,41 & 1,2 \\
\hline Atualização dos estoques & 3,65 & 1,1 & 3,6 & 1,2 & 3,85 & 1,2 & 3,76 & 1,1 \\
\hline Comunicação e propaganda & 3,33 & 1,2 & 3,14 & 1,3 & 3,41 & 1,2 & 3,27 & 1,3 \\
\hline Venda e promoção no canal digital & 3,38 & 1,3 & 3,16 & 1,3 & 3,22 & 1,4 & 3,33 & 1,4 \\
\hline Relacionamento por Redes Sociais & 3,26 & 1,3 & 2,84 & 1,3 & 3,22 & 1,4 & 3,02 & 1,4 \\
\hline Relacionamento com o Cliente & 4 & 1,2 & 4 & 1,2 & 4 & 1,1 & 4,06 & 1,1 \\
\hline
\end{tabular}

Fonte: Elaborado pelos autores (2017) 
Observa-se que para os que não são influenciados por marcas, as estratégias de marketing que obtiveram as cinco melhores médias são, nessa ordem, preço e liquidações $(4,15)$, atendimento na loja $(4,15)$, relacionamento com o cliente $(4,00)$, formas e condições de pagamento $(3,89)$ e ambiente da loja $(3,79)$, para o sexo feminino, e atendimento na loja $(4,53)$, ambiente da loja $(4,23)$, preço e liquidações $(4,16)$, relacionamento com o cliente $(4,00)$ e, por fim, formas e condições de pagamento $(3,77)$, para o sexo masculino. Os resultados mostram que as médias foram parecidas para a maioria dos itens, no entanto, três se destacam com médias próximas de 4, como preço, atendimento e relacionamento com clientes, para ambos os gêneros. No caso dos homens, a variável ambiente da loja se destaca com média acima de 4 e desviopadrão de 0,96 .

Já para as mulheres e homens influenciados por marcas, dentre as cinco principais estratégias citadas estão, atendimento na loja $(4,59)$, preço e liquidações $(4,22)$, formas e condições de pagamento $(4,10)$, ambiente da loja $(4,05)$ e relacionamento com o cliente $(4,00)$, para o sexo feminino, e atendimento na loja $(4,37)$, ambiente da loja $(4,16)$, preço e liquidações $(4,14)$, relacionamento com o cliente $(4,06)$ e, por fim, gestão da marca $(3,82)$, para o sexo masculino. Mesmo para os influenciados por marcas, esta tem médias abaixo de outros fatores do marketing, como preço e relacionamentos, o que confirmam outros dados da pesquisa e de autores de marketing sobre a tendência cada vez maior de não serem mais fiéis às marcas.

Ao comparar-se as principais médias de ambos gêneros, infere-se que as mulheres atribuem maior importância para o preço dos produtos e são mais atraídas por liquidações e promoções desenvolvidas pelos varejistas da moda, com média de 4,15 para as que não são influenciadas por marcas e 4,22 para as que são influenciadas. Em contrapartida aos homens, os quais, como já fora citado anteriormente, não se preocupam tanto com o preço dos produtos. No entanto, para os homens, o atendimento nas lojas foi considerado a estratégia de marketing que deve ser utilizada pelos lojistas da moda, com 4,53 de média para os que não são influenciados por marcas e 4,59 para os que são influenciados. Um fato que justifique tal resultado é a necessidade que o homem tem de receber a maioria das informações possíveis no menor tempo possível dentro do ambiente de compra da loja por não gostarem de demorar nas compras. Os homens querem lugares nos quais consigam encontrar o que precisam com o mínimo de procura para sair rapidamente da loja. Se um homem tiver de perambular e procurar, em outras palavras, fazer compras, provavelmente desistirá frustrado e sairá (UNDERHILL, 2009, p. 134).

O desvio-padrão obtido de cada variável, para os que não são influenciados por marcas, atualização dos estoques $(1,11)$ e ambiente da loja $(1,15)$ foram as variáveis citadas pelas mulheres que apresentaram os desvios-padrão menores e ambiente da loja $(0,84)$ e atendimento na loja $(0,91)$ foram as opções apontadas pelos homens com as notas mais homogêneas. Para os influenciados por marcas do sexo feminino, as estratégias com menores DPs foram atendimento na loja $(0,81)$ e gestão da marca $(0,89)$; já para os homens influenciados por marcas, preço e liquidações $(0,94)$ e ambiente da loja $(0,96)$ foram as que apresentaram os menores DPs também.

Outra questão a ser salientada são os elevados valores obtidos pelo desvio-padrão de questões como divulgação e relacionamento por meio das redes sociais, com 1,30 e 1,27 para as mulheres e homens não influenciados por marcas, e promoções na internet, com 1,37 e 1,35 para as mulheres e homens que são influenciados por marcas, o que caracteriza uma variação significativa na opinião dos diversos respondentes que formaram a amostra em questão. 


\section{CONSIDERAÇÕES FINAIS}

O presente estudo foi realizado com o objetivo de destacar os diferentes fatores que influenciam na escolha de marcas e no comportamento de compra de homens e mulheres no segmento da moda, buscando analisar similaridades e diferenças entre os gêneros. Encontraram-se os principais fatores que influenciam homens e mulheres no momento da compra, bem como, demais questões relacionadas ao ato de comprar, tais como a que é associado ao ato de comprar; quando existe a necessidade da compra; qual a frequência de compra; como é caracterizada a decisão de compra dos consumidores; e quais elementos são levados em conta no que diz respeito ao pós- compra. Com isso, além de compreender os fatores diretamente influenciadores da compra, uma ampla gama de outros aspectos que giram em torno do ato de comprar foram analisados, visando conhecer com maior profundidade os consumidores.

Como resposta a problemática norteadora, identificou-se que as marcas podem sim influenciar homens e mulheres de maneira diferente no comportamento de compra no segmento da moda, pois além de ser uma questão básica de que homens e mulheres possuem comportamentos diferentes em basicamente todos os aspectos de suas vidas, os mesmos reagem diferentemente às ações de marketing realizadas pelas empresas, tais como, as promoções e liquidações que são mais apreciadas por mulheres, que preocupam mais com os preços dos produtos que os homens; e as influências sofridas pelos homens em marcas que já conhecem e costumam comprar.

Como resultados mais significativos, foi comprovado que homens são mais influenciados por marcas que as mulheres, com 53\% do total de homens entrevistados versus $33 \%$ do total das entrevistadas do gênero feminino, entretanto os números indicam uma tendência crescente de não fidelidade às marcas, fenômeno observado nos dias de hoje e comprovado por $47 \%$ dos homens e $67 \%$ das mulheres, que responderam não levar em consideração a marca dos produtos da moda ao comprarem. Também, fato que comprova essa tendência crescente de não fidelidade às marcas são apenas os $7 \%$ das mulheres e $6 \%$ dos homens, do total dos que são influenciados por marcas, que se dizem fiéis a apenas uma marca e, ao os questionarem quais os fatores que os fazem comprar apenas essas marcas, pode-se verificar similaridades entre os gêneros, haja visto que ambos apontaram a qualidade como principal fator, todavia as mulheres apontaram em segundo lugar o design/estilo dos produtos e, os homens, costume e tradição.

Os principais aspectos que apontaram diferenças significativas entre os gêneros, os quais puderam ser constatados na pesquisa, estão, dentre eles, a frequência de compra, principal fonte de busca por informações, elementos avaliados no pós-compra e as estratégias de marketing apontadas pelos consumidores, as quais devem ser desenvolvidas pelas empresas da moda. Já os que apontaram as similaridades mais significativas são: fator necessidade como sendo associado ao ato de comprar, quando surge a necessidade de comprar, não planejarem muito suas compras, baixo índice de não fidelidade a apenas uma marca e, por fim, os principais fatores levados em consideração no momento da compra, como preço e design/estilo dos produtos da moda.

Em se tratando das estratégias de marketing apontadas pelos consumidores que devem ser desenvolvidas pelas empresas da moda pode-se observar diferenças entre os gêneros, pois as mulheres consideraram que o preço e liquidações e o atendimento na loja como os mais importantes, já os homens, consideraram o atendimento e ambiente da loja. O relacionamento com os clientes foram apontados por ambos os gêneros como importantes. 
As limitações do estudo se referem a amostra, que pode ser diversificada, estratificada ou ampliada. Os resultados da pesquisa, quando condensados em segmentos específicos, tendem a variar de acordo com o perfil de entrevistados. Sugere-se realização de estudos futuros por meio de outras formas de pesquisa, levando em consideração o perfil socioeconômico, pois o mesmo não foi o alvo central deste estudo. Cabe reafirmar a fundamental importância deste trabalho e do tema abordado, expondo um contexto atual e que apresenta carência de estudos nessa área, tanto na Região Centro-Oeste, quanto na cidade de Cuiabá, mas que serve de referência para futuras pesquisas científicas nessa área de estudo. Desse modo, conclui-se que todos os objetivos propostos inicialmente foram atingidos, demonstrando rigor, pertinência e relevância na investigação.

\section{REFERÊNCIAS}

AAKER, D. A. Marcas: Brand Equity Gerenciando o Valor da Marca. São Paulo: Negócio, 1998.

ABIT; MDIC. Pesquisa Aponta os Hábitos do Consumidor de Moda Brasileiro. Disponível em: $\quad<\mathrm{http}: / /$ revistacriativa.globo.com/Revista/Criativa/0,,EMI280206-17096,00ESQUISA+APONTA+OS+HABITOS+DO+CONSUMIDOR+DE+MODA+BRASILEIRO. html >. Acesso em: 14 de janeiro de 2014.

ALMEIDA, S. T. A Influência do Humor e da Promoção sobre o Comportamento de Compra por Impulso: Um estudo sobre o consumidor brasileiro. UPMF, Grenoble II, 1992 (Tese de Doutorado).

ANDREASI, D. Arquivo de Etiquetas - Paco Underhill: Por dentro da Zona de Transição. Disponível em: < http://jovemadministrador.com.br/tag/paco-underhill/>. Acesso em: 12 janeiro 2014.

ARAÚJO JR, O. As marcas e o comportamento do consumidor. Disponível em: <http://www.gestordemarketing.com/profiles/blogs/as-marcas-e-o-comportamento-do>. Acesso em: 12 agosto 2013.

BOONE, L; KURTZ, D. Marketing Contemporâneo.12 ed. São Paulo: Ed. Cengage Learning, 2009.

CHURCHILL, G.; PETER, J. P. Marketing: criando valor para os clientes. São Paulo: Saraiva, 2000.

COBRA, M. Algumas reflexões acerca do marketing da moda. RAE Light v. 4, n. 4, p. 2ᄀ5, 1997.

DARLEY, W.; LUETHGE, D.; THATTE, A. Exploring the relationship of perceived automotive salesperson attributes, customer satisfaction and intentions to automotive services department patronage: The moderating role of costumer gender. Journal of Retailing and Consumer Services, 2008, 15: 460-479. 
DARLEY, W.; LUETHGE, D.; THATTE, A. Marketing. 11 ed. São Paulo: Makron Books, 2001.

FECOMÉRCIO-RJ, Pesquisa de Comportamento Aponta que 92\% dos Brasileiros Consomem Moda. Disponível em: <http://www.2dayconsultoria.com.br/2012/01/pesquisade-comportamento-aponta-que-92-dos-brasileiros-consomem-moda/>. Acesso em: 13 de janeiro de 2014.

GIGLIO, E. M. O Comportamento do Consumidor. 3. ed. São Paulo: Thomson Pioneira, 2005.

GIL, A. C. Como Elaborar Projetos de Pesquisa. 5 ed. São Paulo: Atlas, 2010.

GOUVEIA, F. S. et. al. O Marketing e sua importância para o varejo. Revista Científica do ITPAC, v.4, n.1, p.28-39, jan.2011. Disponível em: < http://www.itpac.br/hotsite/revista/artigos/41/4.pdf>. Acesso em: 23 de outubro de 2013.

GROHMANN, M. Z. Relação entre materialismo e estilo de consumo: homens e mulheres com comportamento díspare? Revista Contaduría y Administración, vol. 57, n. 1, México, jan-mar/12: 185-214.

HILLER, M. Os 7 elementos que formam uma marca. Disponível em: $<$ http://www.administradores.com.br/artigos/administracao-e-negocios/os-7-elementos-queformam-uma-marca/64750/>. Acesso em: 2 de outubro de 2013.

IBOPE. Afinidade com as marcas. Disponível em: $<$ http://www.ibope.com.br/ptbr/conhecimento/artigospapers/Paginas/Afinidade-com-a marca.aspx>. Acesso em: 12 de agosto de 2013.

IBOPE. Pesquisa mostra comportamento e hábitos do consumidor brasileiro. Disponível em: < http://www.ibope.com.br/pt-br/noticias/Paginas/Pesquisa-mostra-comportamento-ehabitos-do-consumidor-brasileiro.aspx >. Acesso em: 11 de janeiro de 2014.

KARSAKLIAN, E. Comportamento do Consumidor. São Paulo: Atlas, 2000.

KELlER, K. L.; MACHADO, M., Gestão Estratégica de Marcas. São Paulo: Pearson Prentice Hall, 2006.

KINLEY, T.; CONRAD, C.; BROWN, G. Internal and external promotional references: An examination of gender and product involvement effects in the retail apparel setting. Journal of Retailing and Consumer Services, 1999, 6: 39-44.

KOTLER, P; ARMSTRONG, G. Princípios de Marketing. 7 ed. São Paulo: Ed. Pearson Prentice Hall, 1995.

KOTLER, P. Administração de Marketing. 10. ed. São Paulo: Pearson, 2000. 
KOTLER, P. Administração de Marketing: Edição do novo milênio. São Paulo: Prentice Hall, 2000.

KOTLER, P. Marketing de A a Z: 80 conceitos que todo profissional precisa saber. 7 ed. Rio de Janeiro: Elsevier, 2003.

KOTLER, P. O Marketing Sem Segredos. Porto Alegre: Bookman, 2005.

KOTLER, P; KELLER, K. Administração de Marketing. 12. ed. São Paulo: Pearson Prentice Hall, 2006.

LAS CASAS, A. L. Administração de Marketing: conceitos, planejamento e aplicações à realidade brasileira. São Paulo: Atlas, 2006.

LAS CASAS, A. L.; GARCIA, M. T. Estratégias de Marketing para Varejo: Inovações e Diferenciações Estratégicas que Fazem a Diferença no Marketing de Varejo. São Paulo: Novatec, 2007.

LAS CASAS, A. Marketing: Conceitos, Exercícios e Casos. 8 ed. São Paulo: Ed. Atlas, 2009.

MATTAR, F. Pesquisa de Marketing. São Paulo: Atlas, 2001.

OKAZAKI, S.; HIROSE, M. Does gender affect media choice in travel information search? On the use of mobile internet. Tourism Management, 2009, 30: 794-804.

OLIVEIRA, M. O. R.; LUCE, F. B. O Valor da Marca: Conceitos, Abordagens e Estudos no Brasil. Disponível em: <http://www.scielo.br/pdf/read/v17n2/08.pdf>. Acesso em: 02 outubro 2013.

PEREIRA, P. F. P. Ainda existem consumidores fiéis? Disponível em: < http://www.alumniespm.com.br/impressao/ainda-existem-consumidores-fieis/>. Acesso em: 11 de janeiro de 2014.

PEREZ, C. Signos da Marca: Expressividade e Sensorialidade. São Paulo: Pioneira Thomson Learning, 2004.

PINHO, J. B. O Poder das Marcas. 3. ed. São Paulo: Summus Editorial, 1996.

POPCORN, F; MARIGOLD, L. Público-alvo: mulher. Evolução: 8 verdades do marketing para conquistar sua consumidora do futuro. Rio de Janeiro: Campus, 2000.

SANT'ANNA, A.; ROCHA, I.; GARCIA, L. Propaganda: teoria, técnica e prática. 8 ed. São Paulo: Pioneira, 2009.

SCHIFFMAN, L. G; KANUK, L. L. Comportamento do consumidor. 6 ed. Rio de Janeiro: LTC, 2000. 
SILVA, S. M. A. Comportamentos de Compra de Moda: Uma comparação entre géneros. Disponível em: <http://bdigital.ufp.pt/bitstream/10284/1020/2/Monografia.pdf>. Acesso em: 11 agosto 2013.

SILVA, I. S.; SCHERER, C. B. B. Reposicionamento de Marca no Segmento de Moda. Revista de Marketing, n. 483, ano 46, p. 90-95, julho/agosto 2013.

SOlOMOn, M. R. O Comportamento do Consumidor: Comprando, Possuindo e Sendo. 5. ed. Porto Alegre: Bookman, 2002.

TAN, T.; LING, L.; THENG, E. Gender-role portrayals in Malaysian and Singaporean television commercials: an international advertising perspective. Journal of Business Research, 2002, 55: 853-861.

UNDERHILL, P. Vamos às compras: a ciência do consumo. 16a. ed. Rio de Janeiro: Elsevier, 1999.

UNDERHILL, P. Vamos às compras: a ciência do consumo nos mercados globais.

Rio de Janeiro: Elsevier, 2009.

VERGARA, S. C. Projetos e Relatórios de Pesquisa e Administração. 11 ed. São Paulo: Atlas, 2009.

VIEIRA, L. A Evolução do Conceito de Marketing. Disponível em: $<$ http://www.administradores.com.br/artigos/marketing/a-evolucao-do-conceito-demarketing/39/>. Acesso em: 06 de setembro de 2013.

VIEIRA, V. A. Comportamento do consumidor. Rev. adm. contemp., Curitiba, v. 6, n. dez. 2002. Disponível em: <http://www.scielo.br/scielo.php?script=sci_arttext\&pid=S14 1565552002000300015\&lng=pt\&nrm=iso>. Acesso em: 15 de setembro de 2013. 